\title{
Preparation of homogeneous, bulk nanocrystalline Ni/Mo alloys with tripled Vickers hardness using flame- made metal nanoparticles
}

\section{SUPPORTING INFORMATION}

Institute for Chemical and Bioengineering, ETH Zurich, Wolfgang-Pauli str. 10, 8093 Zurich,

Switzerland

* Correspondence should be addressed to Wendelin J. Stark

Email: wendelin.stark@,chem.ethz.ch;

Fax: +41446331083 
Table S1. Metal composition of the liquid metal precursor and the reference material.

\begin{tabular}{ccccccccc}
\hline Samples $^{\alpha}$ & $\mathrm{Ni}$ & $\mathrm{Mo}$ & $\mathrm{Al}$ & $\mathrm{Fe}$ & $\mathrm{Mn}$ & $\mathrm{Cr}$ & $\mathrm{Co}$ & $\mathrm{W}$ \\
\hline Ni/Mo & 70 & 30 & - & - & - & - & - & - \\
nano-Hastelloy & 79 & 14 & 2 & 4 & 0.7 & 0.3 & & \\
Reference & 57 & 16 & - & 5.5 & 0.5 & 15.5 & 2.5 & 2.5 \\
\hline${ }^{\alpha}$ Compositions given in wt \% & & & & & & \\
\hline
\end{tabular}




\section{Experimental setup}

A schematic representation of the experimental set-up for the fabrication of the non-noble metal alloy nanoparticles at a production rate of $18 \mathrm{~g} \mathrm{~h}^{-1}$. The flame is encased in a porous tube enabling the addition of inert cooling or reactive gases. The flame is operated in a glove box in an $\mathrm{N}_{2}$ atmosphere at an oxygen level of below $100 \mathrm{ppm}$ ( $\left.\mathrm{vol} / \mathrm{vol}\right)$.

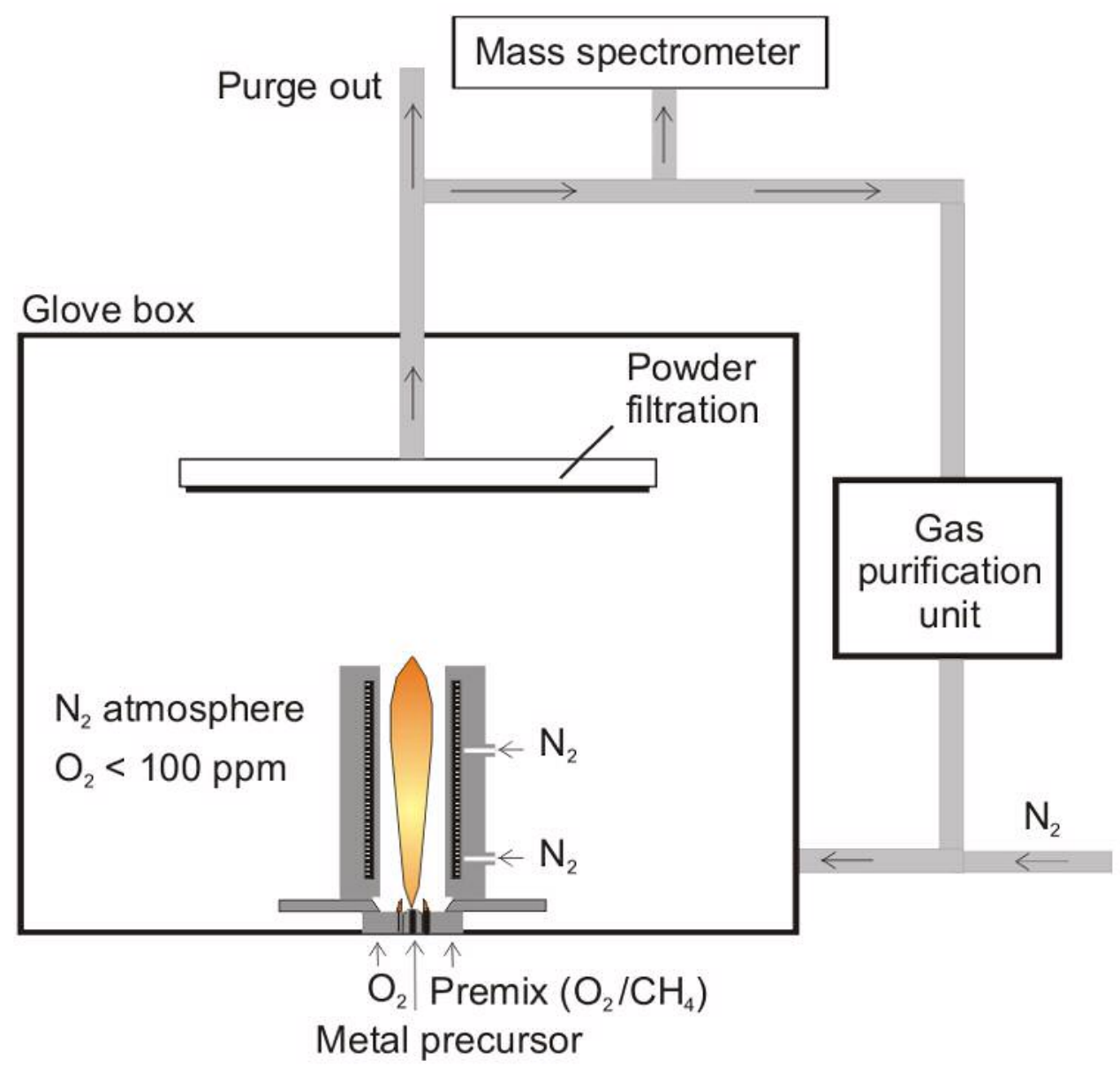

Figure S1. Experimental apparatus for the preparation of non noble metal alloys. 


\section{Element distribution and material homogeneity}

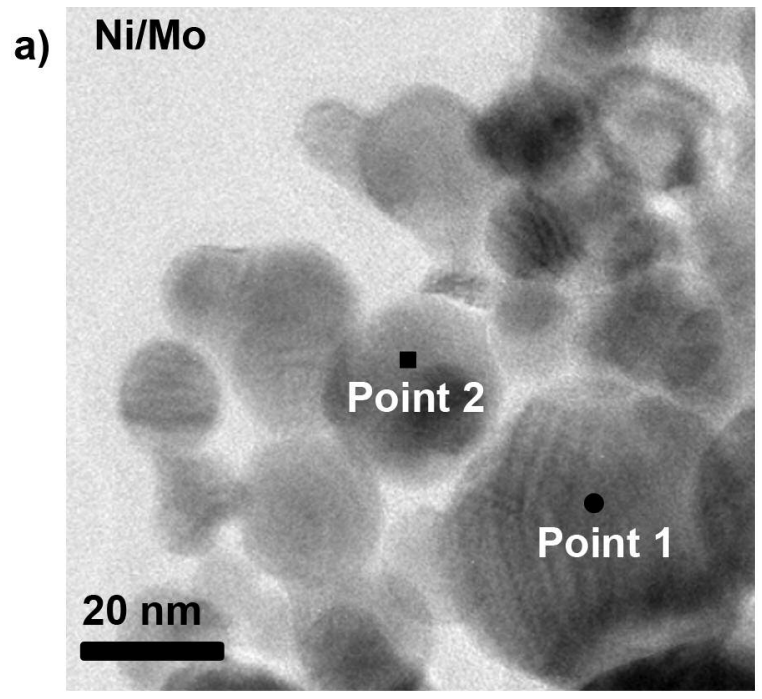

b)

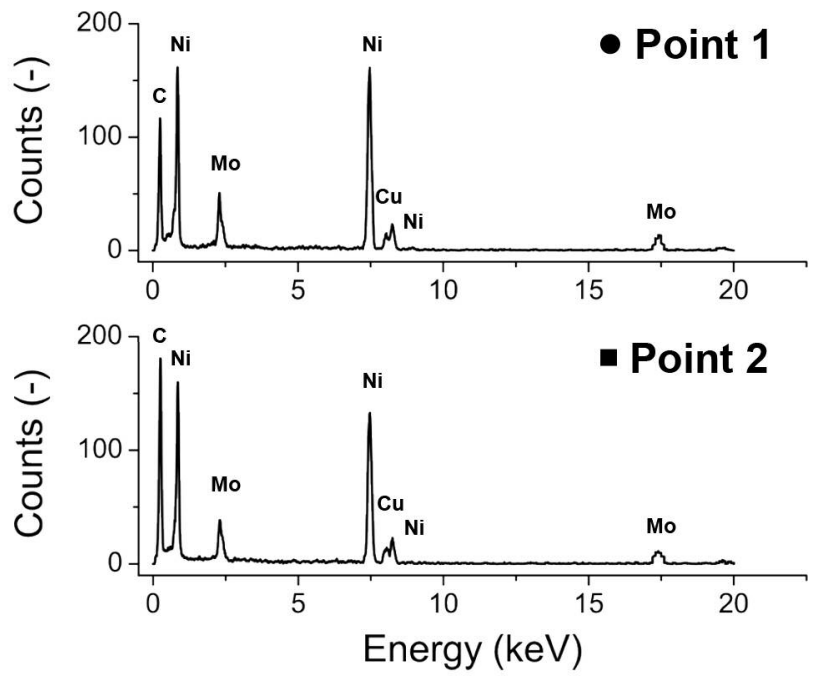

Figure S2. Energy dispersive X-ray spectroscopy showed that reducing flame synthesis resulted in the preparation of metal nickel molybdenum nanoparticles. The presence of carbon and copper on the EDX spectrum is on account of the sample holder (copper grid). 
a)

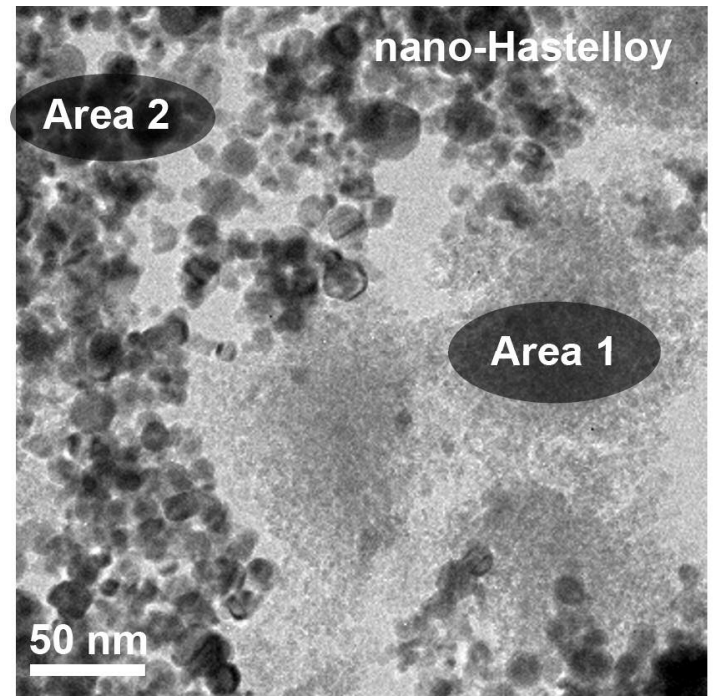

b)

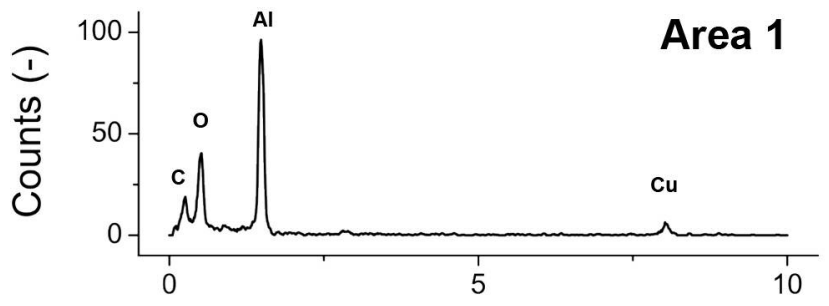

I
Area 2

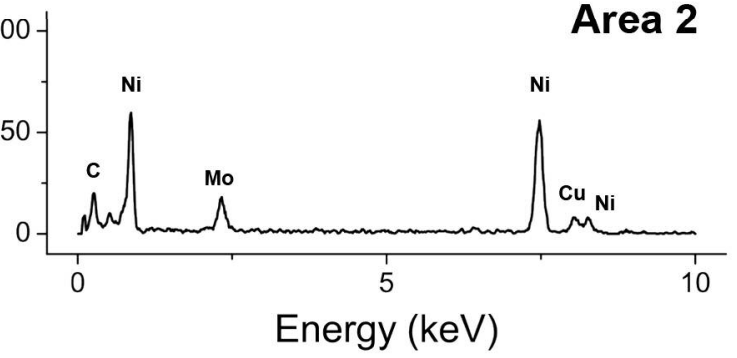

Figure S3. The operating conditions were not reducing enough for the formation of all reduced metallic species. Apart from the production of metal nickel molybdenum nanoparticles (Area 2) alumina was also formed during combustion (Area 1).

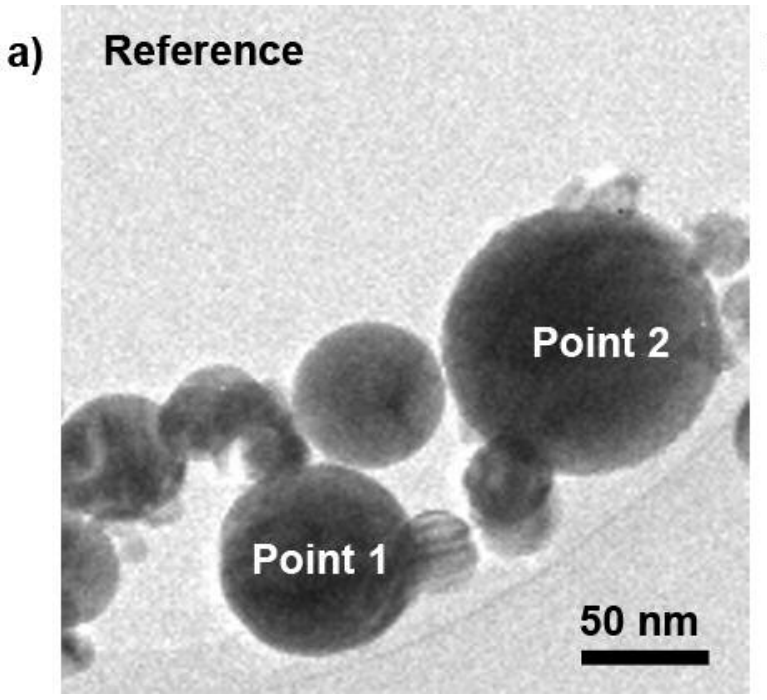

b)

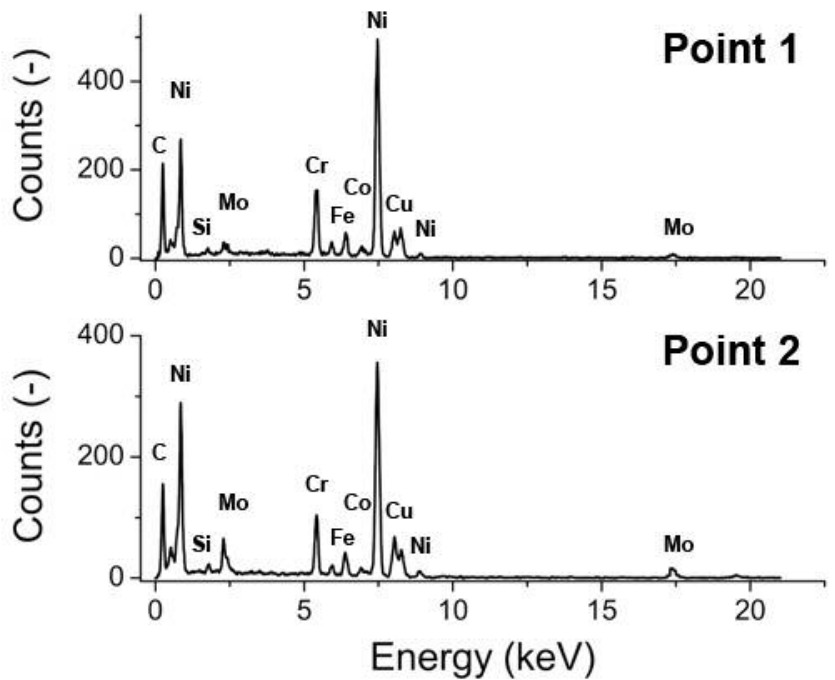

Figure S4. Energy dispersive X-ray spectroscopy of the reference Hastelloy powder revealed the presence of most metal constituents according to Table S1. 


\section{Thermal stability and oxygen content of Ni/Mo}

In order to calculate the oxygen content of the alloy nanoparticles, a sample of $\mathrm{Ni} / \mathrm{Mo}$ $(\mathrm{m}=70.0 \mathrm{mg})$ was sintered under a $7 \mathrm{vol} \% \mathrm{H}_{2}$ in argon up to $750^{\circ} \mathrm{C}$. The reaction step (reduction of the oxide and evolution of water) was monitored by a mass spectrometer allowing detection of all evolving gases.

The reduction of the oxide layer can be described by

$$
\mathrm{MO}+\mathrm{H}_{2} \rightarrow \mathrm{M}+\mathrm{H}_{2} \mathrm{O}
$$

As only the initial concentration of $\mathrm{H}_{2}$ and Ar from all gases in the thermo balance was known the molar flow rate of $\mathrm{H}_{2}$ was calculated by the total gas stream flow rate $(7 \mathrm{vol} \%$ $\mathrm{H}_{2}$ in argon: $6 \mathrm{Lh}^{-1}$ ). Mass spectroscopy data showed a constant concentration of $\mathrm{H}_{2}$ up to $250^{\circ} \mathrm{C}$ revealing that the evolution of water can be attributed to the presence of physisorbed water. At $275^{\circ} \mathrm{C}$ a parallel and rapid evolution of $\mathrm{H}_{2} \mathrm{O}$ revealed the initiation of the reduction of the metal oxide layers. By integrating the area under the $\mathrm{H}_{2}$ flow rate curve the total consumption of hydrogen was calculated to be $0.17 \pm 0.03 \mathrm{mmol}$.

From the total mass decrease of $\mathrm{Ni} / \mathrm{Mo}(4.7 \mathrm{wt} \%)$ and the initial mass of the sample (m $=70 \mathrm{mg}$ ) an oxygen content of $0.20 \mathrm{mmol}$ was calculated. 

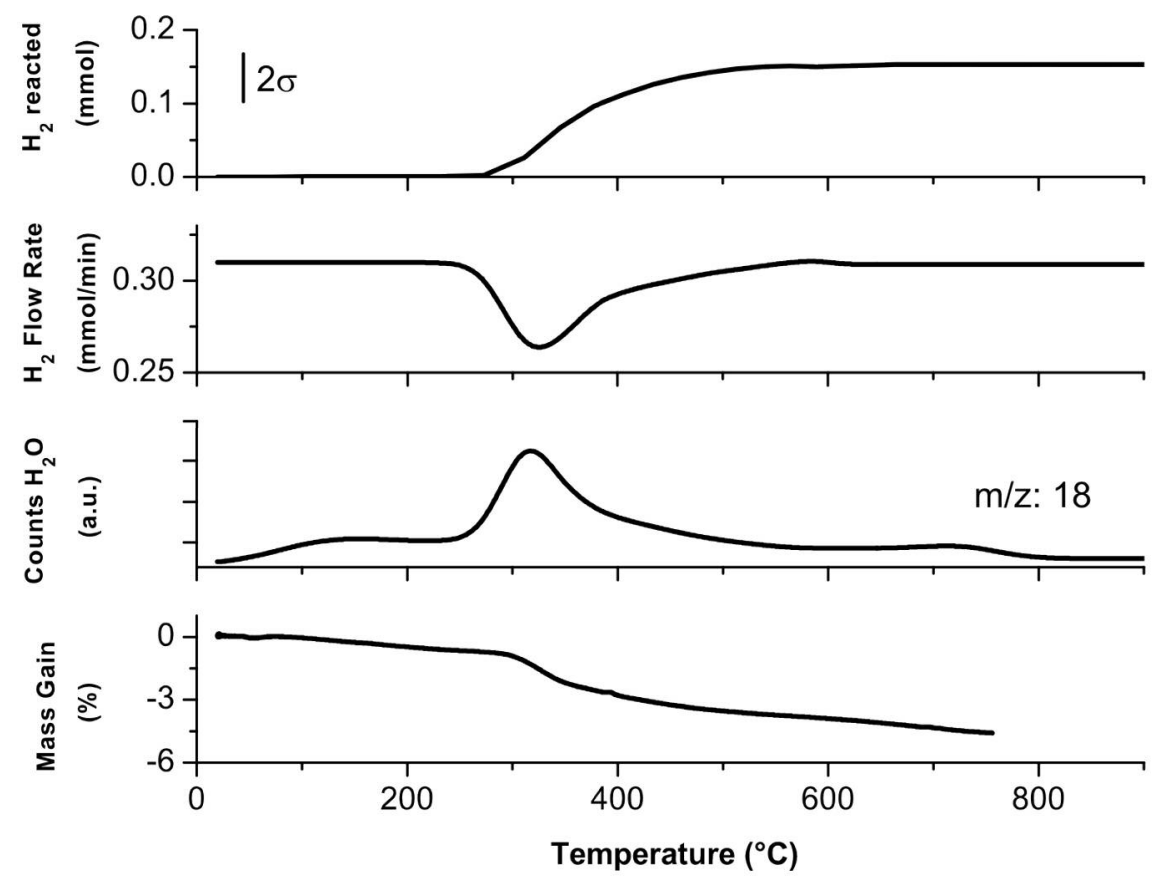

Figure S5. Thermogravimetric analysis of Ni/Mo during in situ reduction by heating in 7 vol \% $\mathrm{H}_{2}$ in argon and simultaneous monitoring of evolving gases by mass spectroscopy. The $\mathrm{m} / \mathrm{z}$ data confirmed the exclusive evolution of water, indicating the reduction of oxide layers covering the nanoparticles at around $300{ }^{\circ} \mathrm{C}$. The total hydrogen consumption (top trace) of $0.17 \pm 0.03 \mathrm{mmol}$ stays in agreement with a mass loss (bottom trace) in the form of oxygen from the oxide layer of 0.20 mmol oxygen. 


\section{Scanning electron microscopy image of as prepared Ni/Mo}

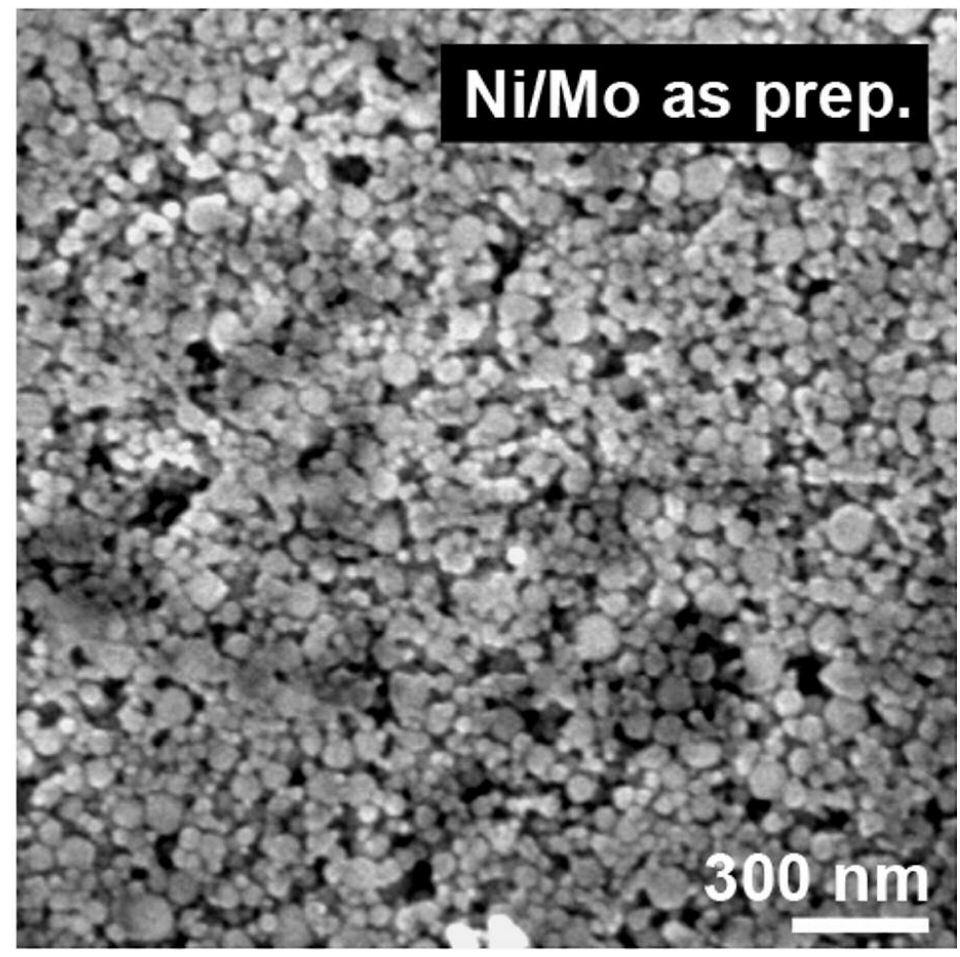

Figure S6. Scanning electron microscopy (SEM) image of a pill out of as prepared Ni/Mo. The uni-axially pressed pill revealed randomly packed metal nanoparticles. 


\section{Thermodynamic calculations}

For the calculation of the Ellingham diagram, the following oxidation reactions were considered, based on standard free Gibbs enthalpy values.

$$
\begin{aligned}
& 2 \mathrm{H}_{2}+\mathrm{O}_{2} \rightarrow 2 \mathrm{H}_{2} \mathrm{O} \\
& 2 \mathrm{CO}+\mathrm{O}_{2} \rightarrow 2 \mathrm{CO}_{2} \\
& 2 \mathrm{Ni}+\mathrm{O}_{2} \rightarrow 2 \mathrm{NiO} \\
& \mathrm{Mo}+\mathrm{O}_{2} \rightarrow \mathrm{MoO}_{2} \\
& 2 \mathrm{Fe}+\mathrm{O}_{2} \rightarrow 2 \mathrm{FeO} \\
& 2 \mathrm{Mn}+\mathrm{O}_{2} \rightarrow 2 \mathrm{MnO} \\
& 4 / 3 \mathrm{Cr}+\mathrm{O}_{2} \rightarrow 2 / 3 \mathrm{Cr}_{2} \mathrm{O}_{3} \\
& 4 / 3 \mathrm{Al}+\mathrm{O}_{2} \rightarrow 2 / 3 \mathrm{Al}_{2} \mathrm{O}_{3}
\end{aligned}
$$

The $\Delta_{\mathrm{r}} \mathrm{G}$ values at elevated temperature were calculated applying the $1^{\text {st }}$ Ulich approximation (1)

$$
\Delta_{r} H^{\circ}(p, T)=\Delta_{r} H^{\circ}\left(p, T_{o}\right)+\int_{T_{o}}^{T} \Delta_{r} C p^{\circ}\left(p, T^{\prime}\right) d T^{\prime}
$$

where

$$
\Delta_{r} C p^{\circ}=0
$$




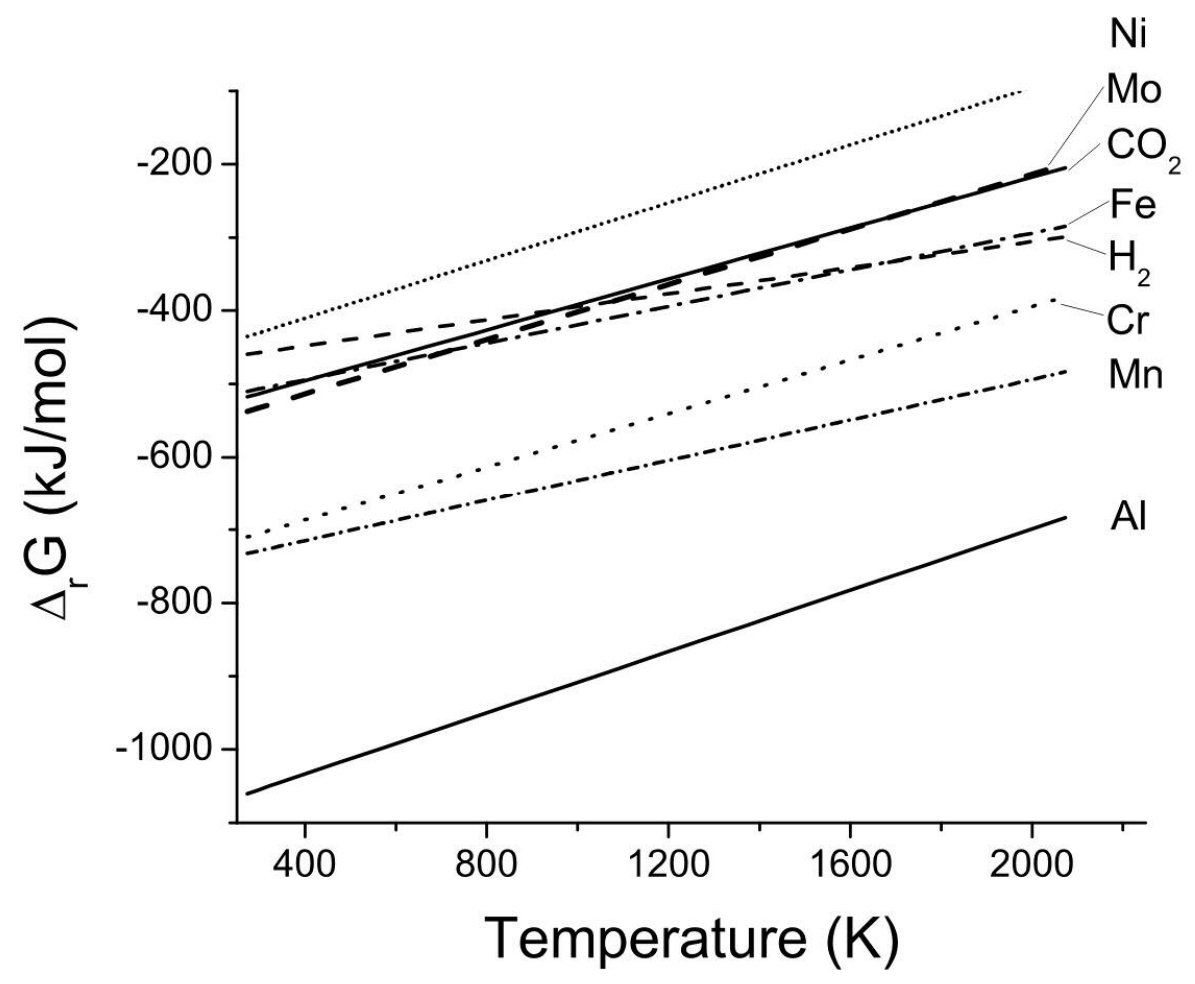

Figure S7. Ellingham diagram of the oxidation reactions of the participated metal and gas components. 